\title{
MICROBIOLOGICAL STUDY AND ANTIBIOGRAM IN CONGENITAL NASOLACRIMAL DUCT OBSTRUCTION- AT A TERTIARY CARE EYE HOSPITAL
}

\author{
Raman Yenugandula1 , Arikari Krishna Krishore², Padmavathi P3
}

${ }_{1}^{1}$ Associate Professor, Department of Ophthalmology, SD Eye Hospital, Hyderabad, Telangana, India.

${ }^{2}$ Assistant Professor, Department of Ophthalmology, SD Eye Hospital, Hyderabad, Telangana, India.

${ }^{3}$ Assistant Professor, Department of Ophthalmology, SD Eye Hospital, Hyderabad, Telangana, India.

\section{ABSTRACT}

\section{BACKGROUND}

Commonest cause for congenital dacryocystitis is obstruction at the lower end of nasolacrimal duct. It is due to an imperforate membrane at the lower end of nasolacrimal duct and usually affects the babies with permanent closure of the Hasner membrane.

The aim of this study was to identify the organisms responsible and to determine the antibiotic sensitivity pattern in case of Congenital Nasolacrimal Duct Obstruction (CNLDO).

\section{MATERIALS AND METHODS}

This descriptive study was conducted on 183 eyes of 175 patients under the age of 2 years attending a Government Tertiary Care Eye Hospital from January 2017 to January 2018. In this study, infants and toddlers attending paediatric OPD with nasolacrimal duct obstruction problems, discharge was collected from the puncta with a moistened sterile swab without touching the lid margin or adjacent skin and sent for culture and sensitivity test. All the patients were kept on antibiotic drops depending on the sensitivity test reports and managed conservatively.

Study Design- Descriptive study.

\section{RESULTS}

Out of 175 patients, Gram +ve cocci constituted the major bacterial isolate $97.0 .1 \%$ with Staphylococcus epidermidis $73.88 \%$ predominating. Most effective antibiotic was Gatifloxacin.

\section{CONCLUSION}

The commonest organism found was Staphylococcus epidermidis sensitive to Gatifloxacin and the conservative treatment of congenital dacryocystitis shows excellent results, providing treatment based on antibiogram.

\section{KEY WORDS}

Congenital Dacryocystitis, Antibiotic Sensitivity, Nasolacrimal Duct Bacterial Isolate, Nasolacrimal Duct Obstruction.

HOW TO CITE THIS ARTICLE: Yenugandula R, Krishore AK, Padmavathi P. Microbiological study and antibiogram in congenital nasolacrimal duct obstruction- at a tertiary care eye hospital. J. Evolution Med. Dent. Sci. 2018;7(44):4765-4769, DOI: $10.14260 /$ jemds/2018/1063

\section{BACKGROUND}

Commonest cause for congenital Dacryocystitis is obstruction at the lower end of nasolacrimal duct. ${ }^{1}$ It is due to an imperforate membrane at the lower end of nasolacrimal duct and usually affects the babies with permanent closure of the Hasner membrane..$^{2,3}$ In more than $90 \%$ of the new-borns, this membrane perforates spontaneously during first $4-6$ weeks. Sometimes, the perforation occurs after $6-12$ months.4,5 After the age of 12 months, probing and syringing to open the Hasner membrane is indicated. 6 This study is conducted at a tertiary care Government Eye Hospital from south India. Most of the cases were already on medications prescribed by General Practitioners, Paediatricians and Ophthalmologists

'Financial or Other Competing Interest': None.

Submission 06-08-2018, Peer Review 14-10-2018,

Acceptance 20-10-2018, Published 29-10-2018.

Corresponding Author:

Dr. Raman Yenugandula,

Associate Professor,

I/C Professor,

Department of Paediatric Ophthalmology,

SD Eye Hospital, Hyderabad

Telangana, India.

E-mail: drraman33@gmail.com

DOI: $10.14260 /$ jemds $/ 2018 / 1063$

\section{(c) (i) $(9)$}

from periphery. Most of the studies pertaining to microbiological and aetiological are devoted to adult patients. Minor number of studies are devoted congenital dacryocystitis. Previous studies conducted have shown changing patterns of causative organisms with time and geographical area. In the present study our aim was to know the common type of bacteria associated with congenital dacryocystitis and their sensitivity, resistance to commonly used antibiotics and guide the clinician in his choice of medication, as only a few studies are available reporting on congenital dacryocystitis and its treatment based on antibiogram. 7,8

\section{MATERIALS AND METHODS}

This descriptive study was conducted on 183 eyes of 175 patients (Out of which 100 were male patients $(57.14 \%)$ and 75 were female patients $(42.86 \%$ patients $)$ attending paediatric ophthalmology clinic at Sarojini Devi Eye Hospital, Hyderabad, during January 2017 to January 2018. Mainly, paediatric cases less than 2 years of age with lacrimation and mucopurulent discharge were included. Cases treated by paediatricians and ophthalmologists which were put on conventional broad-spectrum antibiotics and which did not respond have come to paediatric ophthalmology department at Sarojini Devi Eye Hospital, Hyderabad. After antibiogram 
and proper antibiotic selection, mainly on topical eye drops these cases have improved.

Those cases previously interfered surgically in the past, the cases with punctual abnormalities and lid abnormalities were excluded from this study. Cases with conditions like blepharitis, conjunctivitis and systemic causes like upper respiratory tract infections which lead to watering were also excluded. Age of presentation was from 0 - 24 months. 167 cases (95.43\%) were unilateral and $8(4.57 \%)$ were bilateral. In 96 cases $(54.86 \%)$ right eye was involved, 71 cases $(40.57 \%)$ left eye was involved and 8 cases $(4.57 \%)$ both eyes were involved.

The material for bacteriological analysis was taken from the affected eye in the form of regurgitant material or the conjunctival discharge itself if there was no regurgitation. The material was taken on sterile cotton tipped swabs, was stroked immediately on blood-agar and MacConkey's agar plates and intubated at $37^{\circ} \mathrm{C}$ for 48 hours before declaring them sterile. Organism isolated was then tested for sensitivity to various antibiotics by disc diffusion techniques. ${ }^{9}$ After the sensitivity report, appropriate antibiotic was instituted followed by massage over lacrimal sac area and cleaning of the discharge. This conservative line of treatment was given for a period of 3 months. Complete cure was defined as the absence of watering and discharge, which was achieved by either medical means or surgical means (probing and syringing) in routine clinical practice.

\section{RESULTS}

The bacteriological profile in the cases under study and their antibiotic sensitivity patterns are depicted in the following tables. Positive cultures were obtained in 134 eyes (73.22\%), 49 eyes $(26.78 \%)$ were sterile. Gram positive cocci 130 eyes (97.01\%) were the commonest type of bacteria isolated, of which staphylococcus epidermidis constituted 99 cases (73.88\%) followed by Staphylococcus aureus 16 cases $(11.94 \%)$ and Streptococcus 6 cases $(4.48 \%)$. In this study 100 cases $(57.14 \%)$ were males and 75 cases $(42.86 \%)$ were females with unilateral eye involvement $(95.62 \%)$ was more frequent than bilateral (4.37\%). Fungal isolate (Aspergillus) was identified in single case.

Sensitivity pattern was determined, and most effective antibiotic was Gatifloxacin and Chloramphenicol.

\begin{tabular}{|c|c|c|}
\hline Sex & No. of Cases & Percentage \\
\hline Male & 100 & $57.14 \%$ \\
\hline Female & 75 & $42.86 \%$ \\
\hline \multicolumn{2}{|c|}{ Table 1. Sex Wise Distribution } \\
\hline
\end{tabular}

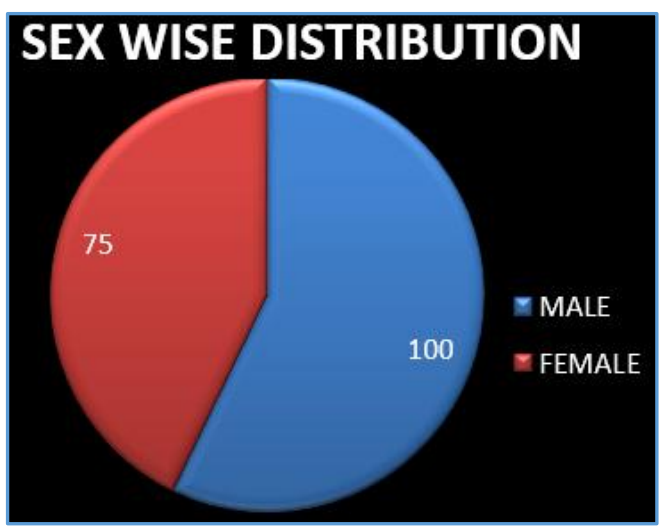

Graph 1. Sex Wise Distribution

\begin{tabular}{|c|c|c|}
\hline Age of Presentation & No. of Cases & Percentage \\
\hline 0-3 months & 22 & $12.57 \%$ \\
\hline 4-6 months & 37 & $21.14 \%$ \\
\hline 7-12 months & 61 & $34.86 \%$ \\
\hline 13-18 months & 12 & $06.86 \%$ \\
\hline 19-24 months & 43 & $24.57 \%$ \\
\hline \multicolumn{2}{|l}{} \\
\hline
\end{tabular}

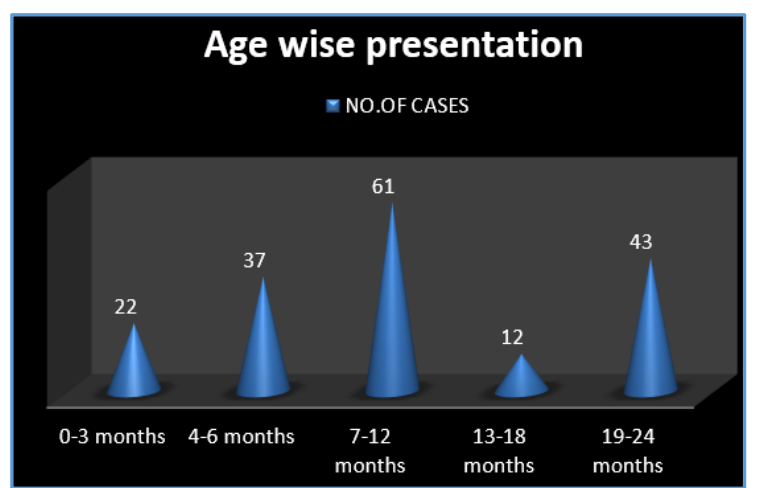

\begin{tabular}{|c|c|c|}
\hline Eyes Involved & No. of Cases & Percentage \\
\hline Unilateral & 167 & $95.43 \%$ \\
\hline Bilateral & 8 & $04.57 \%$ \\
\hline \multicolumn{2}{|c|}{ Table 3. Involvement of Eye } \\
\hline
\end{tabular}

Graph 2. Age Wise Presentation 


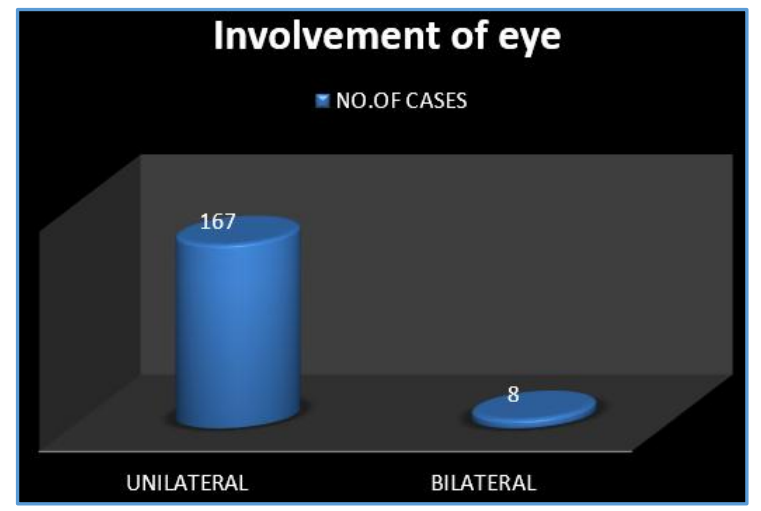

Graph 3. Involvement of Eye

\begin{tabular}{|c|c|c|}
\hline Side & No. of Patients & Percentage \\
\hline Right & 96 & $54.86 \%$ \\
\hline Left & 71 & $40.57 \%$ \\
\hline Bilateral & 08 & $04.57 \%$ \\
\hline \multicolumn{3}{|c|}{ Table 4. Laterality } \\
\hline
\end{tabular}

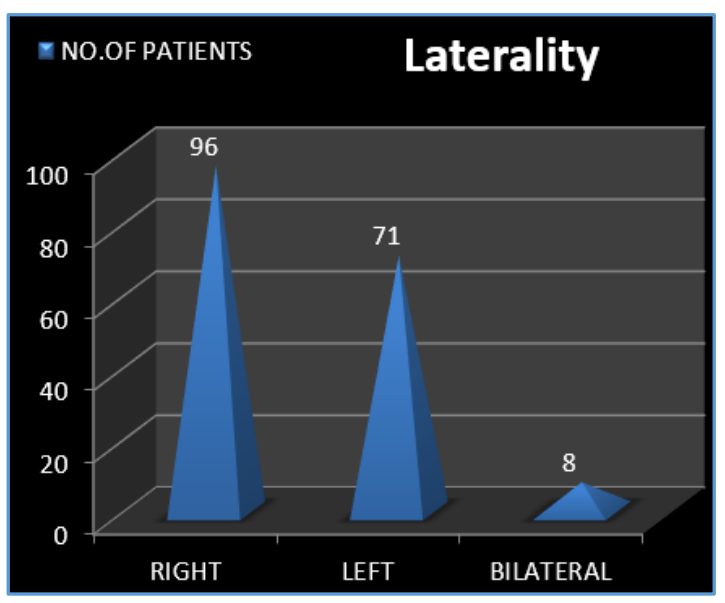

\begin{tabular}{|c|c|c|}
\multicolumn{3}{|c}{ Table 4. Laterality } \\
\hline Bacterial Growth & No. of Eyes & Percentage \\
\hline Positive & 134 & $73.22 \%$ \\
\hline Sterile & 49 & $26.78 \%$ \\
\hline \multicolumn{2}{|r|}{ Table 5. Bacteriological Features } \\
\hline
\end{tabular}

***Fungal Culture - 1 - Aspergillus.

\section{Bacteriological features}

\section{NO.OFEYES}

134

POSITIVE

\section{STERILE}

Graph 5. Bacteriological Features

\begin{tabular}{|c|c|c|}
\hline Organism & No. of Cases & Percentage \\
\hline Enterococcus & 7 & $5.22 \%$ \\
\hline $\begin{array}{c}\text { Enterococcus + } \\
\text { Diplococci }\end{array}$ & 1 & $0.75 \%$ \\
\hline Micrococci & 1 & $0.75 \%$ \\
\hline Pseudomonas & 4 & $2.98 \%$ \\
\hline S. aureus & 16 & $11.94 \%$ \\
\hline S. epidermidis & 99 & $73.88 \%$ \\
\hline Streptococci & 6 & $4.48 \%$ \\
\hline \multicolumn{2}{|c|}{ Table 6. Distribution of Bacterial Isolates } \\
\hline
\end{tabular}

\section{Distribution of bacterial isolates}

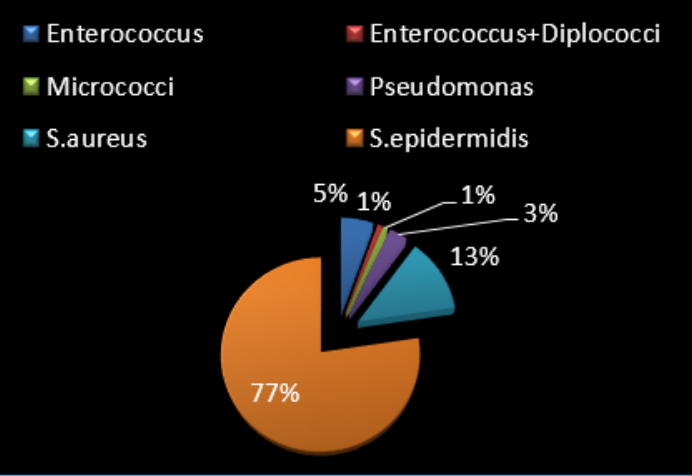

Graph 6. Distribution of Bacterial Isolates

\begin{tabular}{|c|c|c|c|}
\hline Drug & Sensitive & Resistant & Could not be Tested \\
\hline Chloramphenicol & 110 & 24 & --- \\
\hline Ceftazidime & 52 & 72 & 10 \\
\hline Ciprofloxacin & 69 & 64 & --- \\
\hline Ofloxacin & 80 & 54 & -- \\
\hline Gatifloxacin & 112 & 22 & 8 \\
\hline Gentamycin & 108 & 18 & 36 \\
\hline Moxifloxacin & 87 & 11 & 11 \\
\hline Tobramycin & 99 & 24 & \\
\hline \multicolumn{7}{|c|}{ Table 7. Culture Sensitivity of 134 Eyes } \\
\hline
\end{tabular}




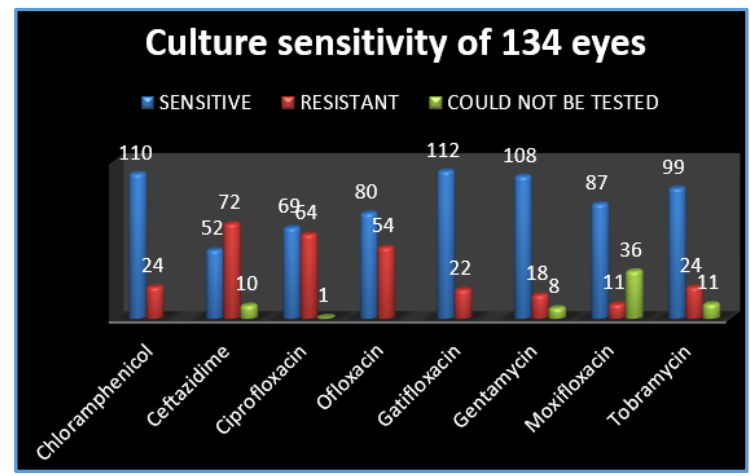

Graph 7. Culture Sensitivity of 134 Eyes

\begin{tabular}{|c|c|c|}
\hline Gram Stain & No. of Isolates & Percentage \\
\hline Gram Positive & 130 & $97.01 \%$ \\
\hline Gram Negative & 4 & $2.99 \%$ \\
\hline \multicolumn{2}{|c|}{ Table 8. Gram Staining Pattern } \\
\hline
\end{tabular}

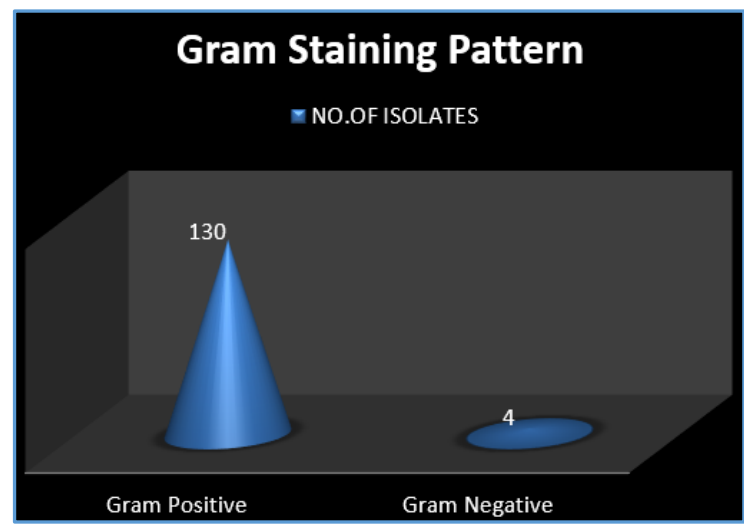

Graph 8. Gram Staining Pattern

Total no. of patients ---- 175

Total no. of eyes ---- 183

\section{DISCUSSION}

Bacteriology of congenital dacryocystitis acquires great significance in view of its bearing on the therapeutics of the disease. This study therefore deals with this problem in a systemic manner.

In our study, 61 cases (34.86\%) had the history of development of symptoms during 7 - 12 months. All of them were less than 2 years of age at the time of presentation. Earlier study by Guerry D et al $^{10}$ found unilateral eye involvement to be $(91.7 \%)$ and bilateral to be $(8.3 \%)$. Our study showed positive culture results in 134 eyes (73.22\%) of samples with Gram positive cocci being the commonest type of bacteria isolated (97.01\% of 130 eyes). Out of these, staphylococcus epidermidis constituted ( $73.88 \%$ of 99 eyes).

The most effective antibiotic against all organisms were Gatifloxacin and chloramphenicol.

Although, staphylococcus epidermidis has been assigned the role of a normal commensal of the conjunctiva along with diphtheroids, a number of reports have appeared of its being pathogenic in postoperative ocular infections, blepharoconjunctivitis and corneal ulcers. ${ }^{11,12,13,14,15}$

Hence, it will be unwise to ignore these organisms as any more as mere commensals. It has also been shown to be associated with congenital dacryocystitis. This study highlights this fact.
Thus, any ocular infection including congenital dacryocystitis should be routinely investigated for staphylococcus epidermidis and its sensitivity pattern. According to antibiogram we changed the topical antibiotics eye drops, majority of them were kept on Gatifloxacin, chloramphenicol, moxifloxacin and tobramycin eye drops for a period of 3 months. The patient's attendants were also trained to do digital massage in the lacrimal sac area. In few cases along with topical, systemic antibiotics and antihistamines were prescribed to control common cold and infection. The cases which have shown sterile cultures were also kept on Gatifloxacin topical eye drops. At the end of 3 months of treatment patients ageing one year and below, 115 patients out of $120(95.8 \%)$ have improved. The 40 patients out of 55 patients of ageing more than 1 year have improved (72\%). Those cases not improved by symptoms and signs like epiphora were taken for lacrimal probing under general anaesthesia at the end of 3 months of treatment. In our present study, we have shown significant positive results under the age of 1 year patients. The fungal isolate probably indicates the injudicious use of antibiotics.

\section{CONCLUSION}

Thus, bacteriology followed by sensitivity testing of various organisms to different antibiotics bears much significance with regards to therapeutics of the disease and guides the clinician better in his choice of medication. Our study therefore has been an attempt in this direction.

\section{REFERENCES}

[1] Zentmayer W. Imperforation of the lachrymonasal duct in the new born and its clinical manifestations. JAMA 1908;51:188-91.

[2] Busse H, Muller KM, Kroll P. Radiological and histological findings of the lacrimal passages of new borns. Arch Ophthalmol 1980;98(3):528-32.

[3] Peterson RA, Robb RM. The natural course of congenital obstruction of the nasolacrimal duct. J Pediatr Ophthalmol Strabismus 1978;15(4):246-50.

[4] Kushner BJ. Congenital nasolacrimal system obstruction. Arch Ophthalmol 1982;100(4):597-600.

[5] Steinkogler FJ, Huber E, Hubar-Spitzy V, et al. The treatment of congenital nasolacrimal duct obstruction. Orbit 1994;13(1):03-10.

[6] Katowitz JA, Welsh MG. Timing of initial probing and irrigation in congenital nasolacrimal duct obstruction. Ophthalmology 1987;94(6):698-705.

[7] Mathew M. Management of congenital dacryocystitis. Indian J Paediatrics 1972;39(3):73-5.

[8] Ghose S. Mahajan VM. Microbiology of congenital dacryocystitis - its clinical significance. J Ocul Ther Surg 1985;4:54-7.

[9] Bauer AW, Kirby WM, Sherris JC, et al. Antibiotic Susceptibility testing by a standardised disk method. Am J Clin Pathol 1966;45(4):493-6.

[10] Guerry D 3rd, Kending EL Jr. Congenital impatency of the nasolacrimal duct. Arch Ophthalmol 1948;39(2):193-204.

[11] Mahajan VM. Acute bacterial infections of the eye: their aetiology and treatment. $\mathrm{Br} \mathrm{J}$ Ophthalmol 1983;67(3):191-4. 
[12] Hurley R. Epidemic conjunctivitis in the new-born associated with coagulase negative staphylococci. J of Obstet and Gynaecol British Common Wealth 1966;73(6):990-2.

[13] Asbell P, Stenson S. Ulcerative keratitis - survey of 30 years' laboratory experience. Arch Ophthalmol 1982;100(1):77-80.
[14] Mahajan VM, Alexander TA, Jain RK, et al. Role of coagulase negative staphylococci and micrococci in ocular disease. J Clin Pathol 1980;33(12):1169-73.

[15] Mahajan VM, Reddy TN, Agarwal LP. Toxigenic strains of staphylococcus epidermidis and their experimental corneal pathogenicity in rabbits. Int Ophthalmol 1982;5(3):155-61. 